\title{
The formation of silica high temperature polymorphs from quartz: Influence of grain size and mineralising agents
}

\author{
Monica Dapiaggi ${ }^{a, *}$, Lucia Pagliari ${ }^{\mathrm{a}, 1}$, Alessandro Pavese $^{\mathrm{a}, \mathrm{b}}$, Luciana Sciascia $^{\mathrm{c}}$, \\ Marcello Merli ${ }^{\mathrm{c}}$, Fernando Francescon ${ }^{\mathrm{d}}$ \\ a Dipartimento di Scienze della Terra, Università degli Studi di Milano, Via Botticelli 23, 20133 Milano, Italy \\ b IDPA-CNR National Research Council, Via Botticelli 23, 20133 Milano, Italy \\ c Dipartimento di Scienze della Terra e del Mare, Università degli Studi di Palermo, Via Archirafi, 22, 90123 Palermo, Italy \\ d Ideal Standard International - C.O.E. - Ceramic Process Technology, Via Cavassico Inferiore 160, I-32026 Trichiana, Belluno, Italy
}

\section{A R T I C L E I N F O}

\section{Article history:}

Received 8 May 2015

Received in revised form 29 July 2015

Accepted 12 August 2015

Available online 7 September 2015

\section{Keywords:}

Silica polymorphs

Phase transition

Mineraliser

\begin{abstract}
A B S T R A C T
The formation of high-temperature silica polymorphs in presence of $\mathrm{Na}$ and $\mathrm{K}$ has been studied at various temperatures and soaking times, starting from quartzes of different grain size, ex situ as well as in situ. The results show that cristobalite and tridymite formation is strongly influenced by the nature and the amount of mineraliser added. In particular, $\mathrm{K}$ seems to discriminate more between the two structures, as it produces the largest observed amount of cristobalite. The disappearance of quartz can be controlled by the proper combination of mineraliser/temperature/time, which in turn control the amount and the type of polymorph formed, together with the amount of amorphous matter. Cristobalite is always the first to form, in agreement with the lower defect formation energy calculated by means of a periodic Linear Combination of Atomic Orbitals hybrid approach (Hartree-Fock and DFT), and tridymite follows, at its expenses. Bearing in mind that the interaction of $\mathrm{Na}$ and $\mathrm{K}$ with a complete ceramic mixture at high temperature is still largely unknown, this paper demonstrates that the high temperature silica polymorphs formation from quartz is easily controllable by means of the addition of known amount of mineralisers.
\end{abstract}

(C) 2015 Elsevier Ltd. All rights reserved.

\section{Introduction}

The theoretical sequence of the silica transformations upon heating involves $\alpha$-quartz, $\beta$-quartz $\left(573^{\circ} \mathrm{C}\right)$, HP-tridymite $\left(870^{\circ} \mathrm{C}\right)$ and $\beta$-cristobalite. The two-letter notation proposed by Nukui et al. [1] in 1978 is used here to describe tridymite structural modifications: the first letter represents the crystal system and the second the unit cell type. Upon cooling, HP-tridymite changes its symmetry from hexagonal to orthorhombic (OC, OS, OP) and to monoclinic (MC) [2], but more structural modifications are possible [2], as a high degree of disorder is present (and clearly visible in the diffuse scattering of the cited polymorphs) [3]. $\beta$-cristobalite, on the other hand, shows a single phase transition during cooling, i.e. to $\alpha$-cristobalite at $270^{\circ} \mathrm{C}$. Even though the only thermodynamically stable phase at room temperature and ambient pressure is

\footnotetext{
* Corresponding author.

E-mail address: monica.dapiaggi@unimi.it (M. Dapiaggi).

1 Now at the Max-Planck-Institut für Kohlenforschung, Mülheim an der Ruhr, Germany.
}

$\alpha$-quartz, metastable $\alpha$-cristobalite is not uncommon. MCtridymite can also be found, but only in presence of alkali-metals impurities [2].

The structures of HP-tridymite and $\beta$-cristobalite are based on 6 -membered rings layers, composed of $\left(\mathrm{SiO}_{4}\right)^{4-}$ corner-sharing tetrahedra; in the hexagonal rings, alternate tetrahedra point up and down. Such layers are stacked on top of each other, linked by the tetrahedra vertexes: the stacking sequence being different for the two silica polymorphs. Tridymite has a twolayer repeat $A B A B A B$ and an hexagonal structure, with layers parallel to the $(001)$ planes. Cristobalite has a three layer repeat $A B C A B C$, which gives a face-centerer cubic structure, with the layers parallel to the (111) planes [5]. Fig. 1 shows a comparison between the stacking sequences of HP-tridymite and $\beta$-cristobalite: in the former, the six-membered rings are stacked in such a way that wide channels are present along the [0 01 ] direction; in the latter, structural 'cages' occur, constituted by one hexagonal ring and plugged by one upward pointing and one downward pointing tetrahedron [4].

High temperature tridymite and cristobalite can also be thought as polytypes, as both structures descend from a different stacking of 


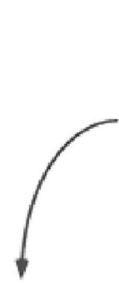

ABAB...

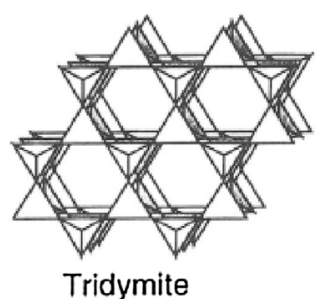

Tridymite
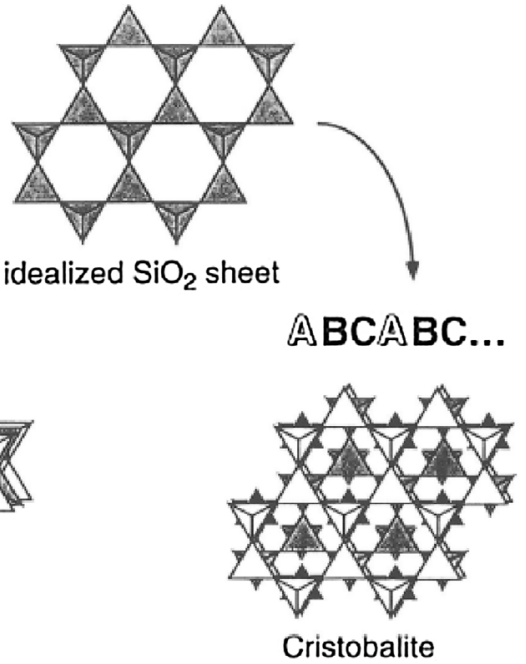

Fig. 1. Comparison of the stacking sequence in idealised cristobalite and tridymite structure. Taken from Ref. [4].

the same module (the six-membered rings layer). Metastable hightemperature silica polymorphs, especially $\alpha$-cristobalite, are often present in ceramic materials, owing to the high-temperature treatment experienced, or to deliberately exploit their peculiar thermal expansion. It is known from literature that the formation of the high-temperature silica polymorphs is favoured by the presence of alkali-metal impurities. Several studies have been published during the last 30-40 years, showing the influence of impurities on the formation of the $\mathrm{SiO}_{2}$ - polymorphs (see Heaney (1994) for a review [2]). Back in 1941, Moseman and Pitzer [6] proved that, when pure quartz is heated, it transforms directly into cristobalite at about $1050^{\circ} \mathrm{C}$, while tridymite forms only if a mineralising agent is present (such as $\mathrm{Na}_{2} \mathrm{CO}_{3}$ ). The same effect has been observed by Pagliari et al. [7], who published a detailed study on the kinetics of the phase transition quartz-cristobalite: according to the quoted authors, the formation of cristobalite from quartz depends on the grain size of the starting quartz. Thermodynamic insight into the transformation of $\beta$-quartz to $\beta$-cristobalite is given by Richet et al. [8], who calculated an equilibrium temperature, from their drop calorimetry measurements, for this transition, of $835^{\circ} \mathrm{C}$; the lowest experimental temperature for the formation of cristobalite is reported by Hill and Roy [9] to be $900{ }^{\circ} \mathrm{C}$, but with the presence of a mineralising agent $\left(\mathrm{Na}_{2} \mathrm{CO}_{3}\right)$.

Venezia et al. [10] showed the influence of alkali metal ions ( $\mathrm{Li}$, $\mathrm{Na}, \mathrm{K}$, and $\mathrm{Cs}$ ) on the crystallisation of the various crystalline forms of silica from an amorphous starting material upon heating: smaller cations ( $\mathrm{Li}$ and $\mathrm{Na}$ ) can produce crystalline silica polymorphs even when added in modest quantities (Li promotes the formation of quartz at $800^{\circ} \mathrm{C}$, and of quartz and cristobalite at $1000^{\circ} \mathrm{C}$, while $\mathrm{Na}$ favours the formation of cristobalite at $1000^{\circ} \mathrm{C}$ ). Large ions ( $\mathrm{K}$ and Cs) need to be added in a greater amount (even 4 times as much) to induce crystallisation of the glass phase. $\mathrm{K}$ promotes the formation of a mixture of cristobalite and tridymite at $800{ }^{\circ} \mathrm{C}$, and of a larger amount of tridymite and a smaller amount of cristobalite at $1000^{\circ} \mathrm{C}$. The large cation Cs does not induce the complete crystallisation of the silica glass, but it favours the formation of cristobalite (with a large amount of amorphous silica) at $800^{\circ} \mathrm{C}$, and of a mixture of cristobalite and tridymite (with a small amount of amorphous silica) at $1000^{\circ} \mathrm{C}$. More recently, a study on the crystallisation of glass-ceramic [11] in the $\mathrm{K}_{2} \mathrm{O}-\mathrm{Na}_{2} \mathrm{O}-\mathrm{B}_{2} \mathrm{O}_{3}-\mathrm{SiO}$ system, with the addition of $\mathrm{TiO}_{2}, \mathrm{Cr}_{2} \mathrm{O}_{3}$ and $\mathrm{LiF}$, showed that, with no addition at $1000^{\circ} \mathrm{C}$, for $1 \mathrm{~h}$, cristobalite formation is promoted, accompanied by little tridymite; the same happens with the addition of $\mathrm{Cr}$ and Ti. On the other hand, the smaller Li ion induces, during the same thermal treatment, the formation of tridymite with very little cristobalite.

Formation of cristobalite and tridymite may be exploited to properly "tune" the thermal expansion of a ceramic body, in order to make it match the one of the glaze, thus avoiding the appearance of flaws due to a mismatch between inner bulk and surface. Upon cooling, $\beta$-cristobalite turns into its tetragonal $\alpha$-phase at $270^{\circ} \mathrm{C}$, as the reconstructive transition to $\alpha$-quartz is kinetically sluggish. $\alpha$ - and $\beta$-cristobalite have average bulk thermal expansion values of 91.7 and $6 \times 10^{-6}{ }^{\circ} \mathrm{C}^{-1}$, respectively [12]. This affects the shrinkage upon cooling and plays a relevant role on the quality of the final product [13]. Tridymite is still largely unknown in terms of thermal expansion properties, which are not reported by Fei [12] and, to the authors' knowledge, have not been published yet. This paper aims primarily at the study of the conditions at which cristobalite and tridymite form from industrial-grade quartz, as a function of particle-size-distributions (PSD), mineraliser ( $\mathrm{Na}$ and $\mathrm{K}$ hydroxyde) and time/temperature conditions of interest to ceramic transformations. The reaction mechanism is also studied by means of in situ high-temperature X-ray powder diffraction, either with laboratory equipment, or with synchrotron radiation. The volumetric thermal expansion values of tridymite are an interesting by-product of this paper. Quantum mechanic calculations (a periodic Linear Combination of Atomic Orbitals hybrid approach based on Hartree-Fock and DFT [14]) are here used as a complementary technique to help understanding the incorporation of $\mathrm{Na} / \mathrm{K}$ by the two high-temperature polymorphs.

\section{Experimental}

In the present investigation three powder quartz samples, SA10S, SA250S, and SA600 (Sibelco), with different PSDs, were used, as shown in Table 1 . The crystallite size and RMS microstrain values were determined using the software MAUD [15]. Such samples were used in a previous investigation by the same authors [7], and their characteristics are reported again in Table 1 for the sake of clarity.

\subsection{High temperature ex situ and in situ experiments}

About $5 \mathrm{~g}$ of each powder were mixed with $1.8 \mathrm{ml}$ of $20 \% \mathrm{wt}$ aqueous sodium or potassium hydroxide solution, in order to obtain a viscous blend, as in industrial processes, and treated at high temperatures in a LKN-S86 Nannetti muffle furnace at 900, 1000, 1100 and $1200^{\circ} \mathrm{C}$. After soaking times of 1 and $6 \mathrm{~h}$, the samples were cooled slowly down to ambient conditions and ground in a MM400 Retsch zirconia ball mill for X-ray powder diffraction data collections. In this way, a total number of 48 samples were produced ex situ and analysed.

The SA600 powder was wetted, in the way described above, with the same amount of $\mathrm{NaOH}$ and $\mathrm{KOH}$ solutions, in order to make two new samples for in situ high temperature experiments. Heating ramps were performed by a $\theta-\theta$ geometry Philips X'Pert diffractometer, equipped with a HTK 16MSW Anton-Paar high-temperature chamber, to understand the transformations occurring at high temperature. Data collections were preliminarily carried out every $50^{\circ} \mathrm{C}$ from room conditions up to $1300^{\circ} \mathrm{C}$, in a narrow range of diffraction angles $\left(19.5-27^{\circ} 2 \theta\right)$. Full measurements were performed between 15 and $75^{\circ} 2 \theta$ every $20^{\circ} \mathrm{C}$ from 800 to $1200^{\circ} \mathrm{C}$. The step size and the counting step were $0.03^{\circ} 2 \theta$ and $1 \mathrm{~s} /$ step, respectively.

\subsection{X-ray powder diffraction}

In order to estimate the glass content by means of coupled Rietveld-RIR refinements [16], 10\% wt of corundum was added 
Table 1

Granulometric characterisation of the starting powders. $\left\langle D_{v}\right\rangle$ and RMS strain come from the analysis of the powder diffraction peak broadening [7].

\begin{tabular}{lccccc}
\hline Sample & $<d>(\mu \mathrm{m})$ & $\mathrm{D} 50(\mu \mathrm{m})$ & Mode $(\mu \mathrm{m})$ & $\left\langle\mathrm{D}_{\mathrm{v}}>(\mathrm{nm})\right.$ & $\begin{array}{l}\text { RMS strain } \\
\left(10^{-4}\right)\end{array}$ \\
\hline SA10S & 28.38 & 23.42 & 50.22 & $270(3)$ & $3.81(5)$ \\
SA250S & 15.78 & 10.90 & 23.81 & $230(3)$ & $3.72(6)$ \\
SA600 & 4.135 & 2.689 & 2.787 & $167(1)$ & $3.48(7)$ \\
\hline
\end{tabular}

to the samples as an internal standard. The reliability of the method has been recently tested with large glass content mixtures [17]. A $\theta-2 \theta$ Bragg-Brentano PANalytical X'Pert Pro diffractometer with a $\mathrm{Cu}-\mathrm{K} \alpha$ radiation source $(\lambda=1.5418 \AA)$ and a multi-channel $X$ 'Celerator detector was used to collect the patterns, which were investigated over the range $5-80^{\circ} 2 \theta$. The step size and the counting time chosen for recording were of about $0.017^{\circ} 2 \theta$ and 30 s per step, respectively, while the divergence and the anti-scatter slits were both opened of $0.5^{\circ}$.

\subsection{Tridymite thermal expansion}

The data were collected at the beam line ID22 (European Synchrotron Radiation Facility; experiment MA2315), with a hot air blower (maximum temperature of about $1000^{\circ} \mathrm{C}$ ) and a wavelength of $0.29501 \AA$. The experimental setup of the beam line has been described in details elsewhere [18]. The Rietveld refinements were performed with the software MAUD [15].

\subsection{Computational}

$\mathrm{Ab}$ initio Linear-Combination-of-Atomic-Orbital calculations (HF/DFT-CRYSTAL09 software [14]) have been performed in order to estimate the energetic cost related to the introduction of $\mathrm{Na}$, or $\mathrm{K}$, in tridymite and cristobalite. We have adopted a Hamiltonian based on the WC1LYP scheme [19], which contains a hybrid Hartree-Fock/density functional exchange-correlation term that mixes the WCGGA exchange component [20], with the exact nonlocal HF exchange contribution and models correlation energy via the Lee-Yang-Parr GGA functional [21]. We have used a hybridisation rate (HR) of 0.16 , and the following values for the tolerances governing the accuracy of the integrals of the self-consistent-fieldcycles: $10^{-6}$ for Coulomb overlap, $10^{-6}$ for Coulomb penetration, $10^{-6}$ for exchange overlap, $10^{-6}$ for exchange pseudo-overlap in direct space and $10^{-14}$ for exchange pseudo-overlap in reciprocal space. The reciprocal space has been sampled according to a regular sub-lattice with a shrinking factor IS equal to 6 corresponding to $112 k$-points through the irreducible Brillouin zone.

The convergence of the geometry optimisation process depends on the root-mean-square (RMS) and absolute value of the largest component of both the gradients and nuclear displacements. The thresholds for the maximum and the RMS forces (the maximum and the RMS atomic displacements) have been set at 0.00025 and 0.00020 a.u. and those for the maximum and the RMS atomic displacements at 0.00130 and 0.00100 a.u. Relaxation terminates when all four conditions are fulfilled. Dissolution of $\mathrm{Na} / \mathrm{K}$ in tridymite and cristobalite has been modeled by a replacement of one $\mathrm{Si}$-atom with four $\mathrm{Na} / \mathrm{K}$-atoms, entering the empty large cages of tridymite and cristobalite.

Super-cells of 16 cation sites have allowed us to model $\mathrm{Na} / \mathrm{K}$ dispersion in both tridymite and cristobalite. Larger super-cells do not affect significantly the results with respect to the ones here shown.

\section{Results and discussion}

As a first step in the study of tridymite formation, several experiments have been performed by heating ex situ at various temperatures and by analysing the products, as described in Section 2. It was already known that, by simply heating all the quartz samples, only cristobalite would form [7]. It was also well known (see the Section 1 for more details) that mineralisers, such as sodium or potassium ions could influence the reactivity, so that other polymorphs (e.g. tridymite) form during the heating or cooling stage.

\subsection{Ex situ results}

The ex situ results will be divided into several sections, as a function of the parameter that is correlated to the formation of high-temperature silica polymorphs.

\subsubsection{Influence of temperature and time}

In Fig. 2, we show the results for the finest sample $(4 \mu \mathrm{m})$ as a function of temperature $\left(900-1200^{\circ} \mathrm{C}\right)$ and soaking time $(1-6 \mathrm{~h})$. It appears clear that, at $900^{\circ} \mathrm{C}$, the amount of quartz is still very high for all time/mineraliser combinations.

Let us now focus on Fig. 2(a), i.e. the one in which $\mathrm{KOH}$ was used as a mineraliser. Quartz is still present at $1000^{\circ} \mathrm{C}$, though it halves after $6 \mathrm{~h}$ soaking time with respect to $1 \mathrm{~h}$ soaking time, and it almost disappears (less than $2 \% \mathrm{wt}$ ) at $1100^{\circ} \mathrm{C}$. At $1100^{\circ} \mathrm{C}$ the ratio cristobalite/tridymite depends on the soaking time: it is favourable to the former for $1 \mathrm{~h}$ firing, and to the latter for $6 \mathrm{~h}$; at $1200^{\circ} \mathrm{C}$, the differences between the two soaking times get less relevant. Fig. 2(b), for which $\mathrm{NaOH}$ was used as the mineraliser, shows a much smaller amount of residual quartz at $1000^{\circ} \mathrm{C}$, with respect to $\mathrm{KOH}$, at $1 \mathrm{~h}$ as well as at $6 \mathrm{~h}$ soaking time. The amount of cristobalite is large only at $1000^{\circ} \mathrm{C}$ or $1 \mathrm{~h}$ soaking time, while for the other time/temperature combinations cristobalite becomes a minor phase, with tridymite as the major one.

\subsubsection{Influence of grain size}

Let us now compare the results for the three quartz PDS samples at $1000^{\circ} \mathrm{C}$, and $1200^{\circ} \mathrm{C}$, as they are the most effective conditions to bring to light the transformations occurring in our samples.

Fig. 3 shows the influence of grain size at $1000^{\circ} \mathrm{C}$. In the case of $\mathrm{KOH}$ as mineraliser and $1 \mathrm{~h}$ soaking time, quartz is still the major phase at $1000^{\circ} \mathrm{C}$, regardless of the particle size, with the exception of a small amount of cristobalite in the $16 \mu \mathrm{m}$ sample. Quartz is still present (though in minor amounts) for a soaking time of $6 \mathrm{~h}$, where the major phase becomes cristobalite, accompanied by tridymite between 5 and 15\% wt. Fig. 3(b), i.e. with $\mathrm{NaOH}$ as a mineraliser, shows that $1 \mathrm{~h}$ soaking time at $1000^{\circ} \mathrm{C}$ gives results that look like those obtained with $\mathrm{KOH}$ and a larger soaking time: cristobalite becomes the major phase, quartz reduces its presence (although with some differences among the samples), and tridymite starts to appear in non-negligible amounts. The lowest quartz content is observed in the finest sample; it increases for the medium size sample, and then decreases in the coarsest sample. If one looks at Fig. 3(a) for the $6 \mathrm{~h}$ soaking time and $\mathrm{KOH}$ as a mineraliser, quartz reaches its maximum in the finest sample, and it decreases with the increase of the grain size. At $6 \mathrm{~h}$ soaking time, quartz has almost disappeared, tridymite being the major phase, with an amount of cristobalite between about 10 and about $18 \%$ wt. The glass-phase contents are similar to each other in the three samples.

Fig. 4 shows again the influence of grain size as in Fig. 3, but the temperature in this case is $1200^{\circ} \mathrm{C}$. It appears clear that quartz is negligible in all the combinations time/temperature/grain size. There are no significant differences in the phase ratios among the samples. 


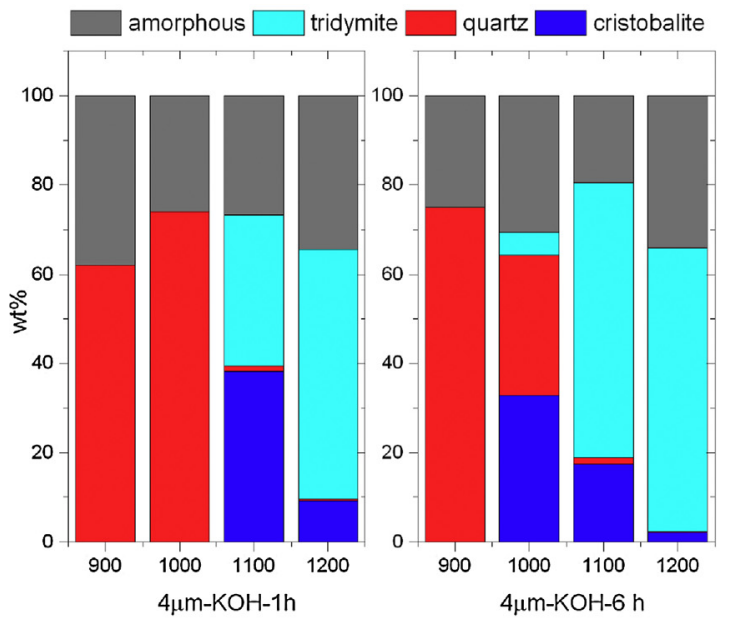

(a) $\mathrm{KOH}$

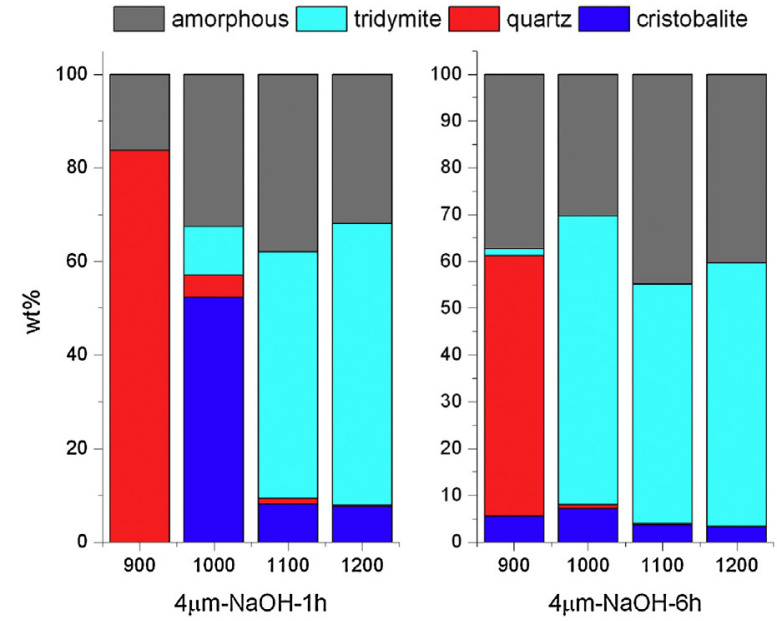

(b) $\mathrm{NaOH}$

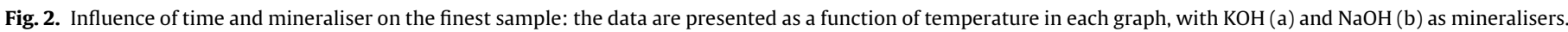
$1 \mathrm{~h}$ soaking time on the left hand side of each half, $6 \mathrm{~h}$ soaking time on the right.

Fig. 5 helps understanding the influence of the grain size on the final output, by displaying the total amount of crystalline phases that develop upon heating. In general, high temperature boosts crystallisation, but a crucial role is played here by the mineraliser, as clearly appreciable by comparing the left with the right hand side of the picture.

A further question is why one observes so large a content of amorphous material, in conditions of time/temperature that should lead to crystallisation. In this view, we have investigated the formation of crystalline phases as a function of the content of mineraliser.

By looking at Fig. 6(a) it is apparent a direct relationship between the amount of mineraliser and that of amorphous phase formed during the heating/cooling process. The experiments were performed on the finest sample, i.e. $4 \mu \mathrm{m}$, at $1000^{\circ} \mathrm{C}$, and $6 \mathrm{~h}$ soaking time. One gathers that the larger the content of mineraliser, the larger the amorphous phase amount. A large enough amount of mineraliser gives a totally amorphous final material, while smaller quantities of mineraliser end up in a quasi-fully crystalline mixture. However, if the mineraliser amount is too small, at $1000^{\circ} \mathrm{C}$, the mixture is almost entirely composed of quartz, so no high temperature polymorph was formed.

From a 2nd order polynomial fit, the amount of amorphous material (in \% wt), at $1000^{\circ} \mathrm{C}$ for $6 \mathrm{~h}$ soaking time, can be related to the moles of mineraliser $(x ; 0-0.08 \mathrm{~mol})$ added:

for $\mathrm{NaOH}:-24025 x^{2}+3099 x\left(R^{2}=0.9834\right)$

for $\mathrm{KOH}:-33879 x^{2}+3744 x\left(R^{2}=0.9889\right)$.

Fig. 6(b) shows the amount of tridymite and cristobalite formed during heating/cooling as a function of the amount of mineraliser added. One observes that

- Na is a much more efficient booster of tridymite than $\mathrm{K}$ (with $\mathrm{NaOH}$ we have a maximum of more than $60 \%$ wt of tridymite, with $\mathrm{KOH}$ a maximum of $8 \% \mathrm{wt}$ );

- the maximum amount of cristobalite can instead be found for $\mathrm{KOH}$ as the mineraliser (about 36\% wt with $\mathrm{K}$ against about $30 \%$ wt with $\mathrm{Na}$ );

- the most favourable combination, in term of the highest content of high temperature crystalline phases and the lowest of amorphous material, seems to be, at $1000^{\circ} \mathrm{C}$, and $6 \mathrm{~h}$ soaking time, the addition of about $0.08 \mathrm{~mol}$ of $\mathrm{NaOH}$, which gives about $36 \%$ wt of cristobalite, about $30 \%$ wt of tridymite, and about $27 \%$ wt of amorphous material.

In view of all the results, we have explored the conditions that maximizes formation of tridymite, obtaining that one has to use the finest quartz, with $0.04 \mathrm{~mol}$ of $\mathrm{NaOH}$, heating at $1200^{\circ} \mathrm{C}$, for $6 \mathrm{~h}$. In so doing, one has the following phase composition: $74.5 \%$ wt of tridymite, $6.5 \%$ wt of cristobalite, and $19 \%$ wt of amorphous material.

The tridymite in this sample was then heated up to about $1000^{\circ} \mathrm{C}$, in $100^{\circ} \mathrm{C}$ steps, in order to evaluate its thermal expansion properties.

\subsection{Tridymite thermal expansion}

In Fig. 7 the volumetric expansion of the unit cell of tridymite is reported. The $\alpha-\beta$ phase transition can be seen between 400 and $500^{\circ} \mathrm{C}$. The thermal expansion coefficient can be calculated from the first order parameter in the polynomial fit by means of the usual

$\alpha=\frac{1}{V}\left(\frac{d V}{d T}\right)$.

The second order polynomials used in the best fit of the data are reported in Fig. 7. The coefficients of thermal expansion for tridymite are: $147 \times 10^{-6}$ until $400^{\circ} \mathrm{C}$, and $11.5 \times 10^{-6}$ beyond $500^{\circ} \mathrm{C}$.

A comparison with cristobalite reveals that tridymite has larger thermal expansion coefficients over both intervals. In the high temperature regime, tridymite $\alpha$ value is almost twice cristobalite's, whereas in the low temperature range the difference is about $46 \%$. Such a higher sensitivity to temperature of tridymite, with respect to cristobalite, hints at a likely larger responsivity to the presence of additives, like $\mathrm{Na}$ and $\mathrm{K}$, and at an increased capability of tridymite to incorporate chemical species upon heating.

\subsection{In situ results}

After having studied the relationship between grain size, time, temperature, and amount and type of mineraliser with the ex situ 

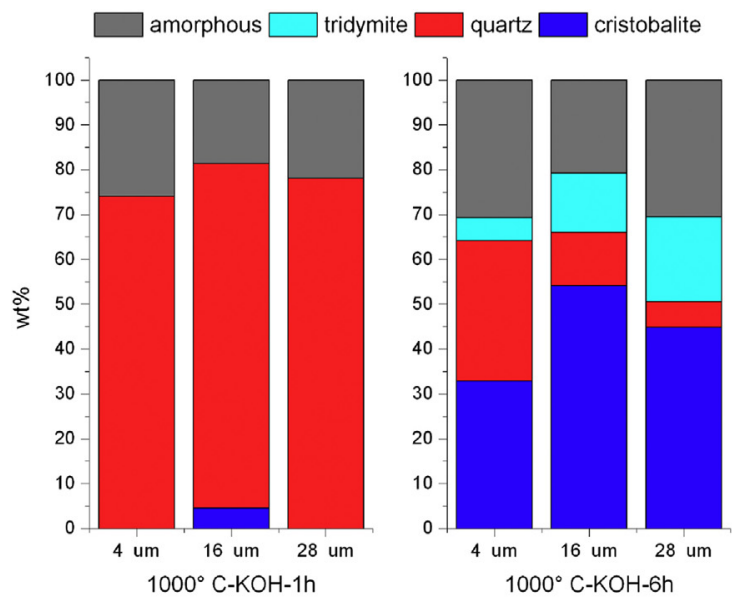

(a) $\mathrm{KOH}$
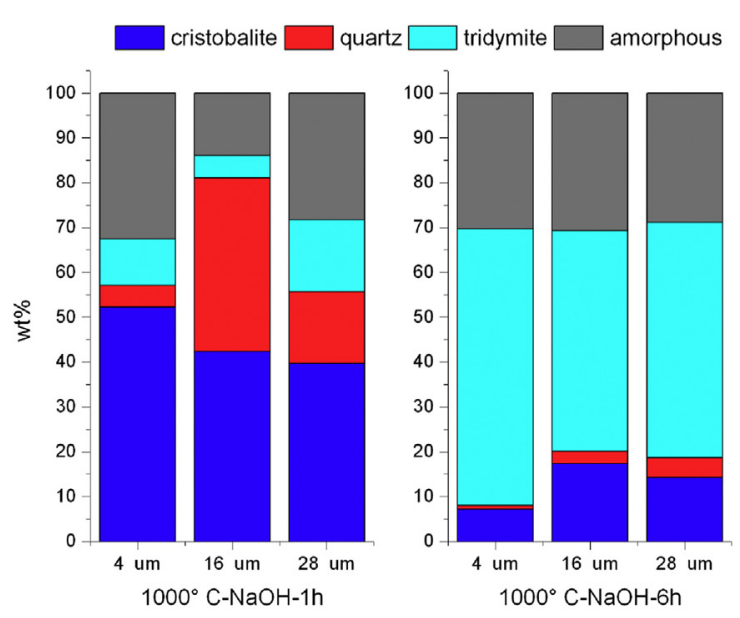

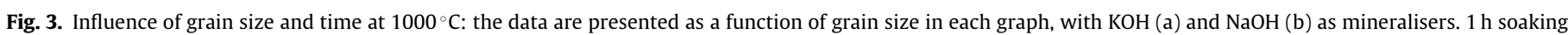
time on the left hand side of each half, $6 \mathrm{~h}$ soaking time on the right.

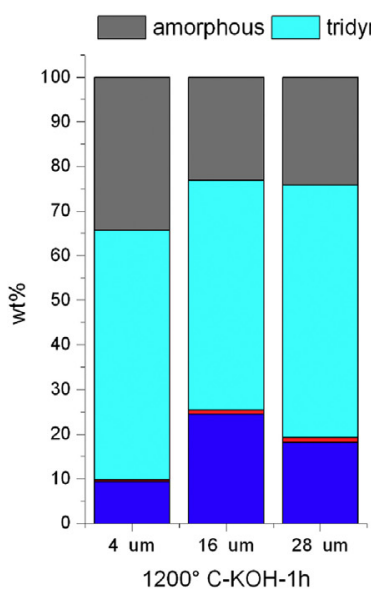

(a) $\mathrm{KOH}$
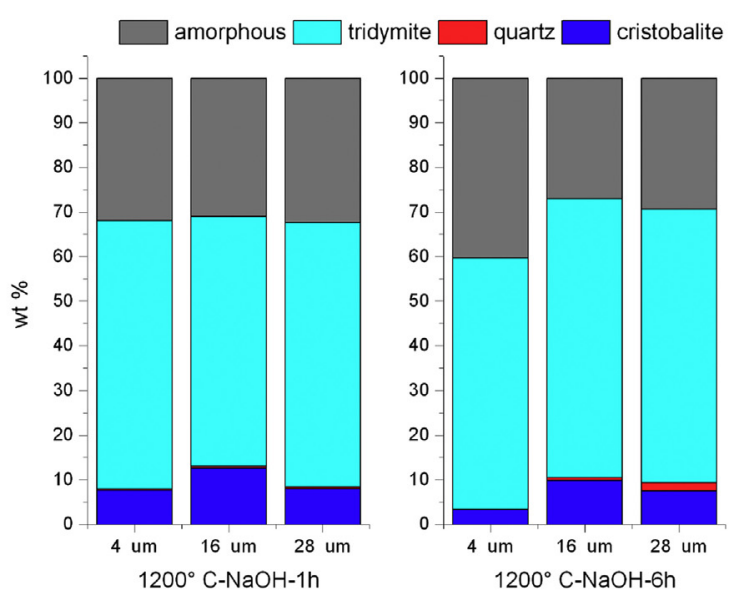

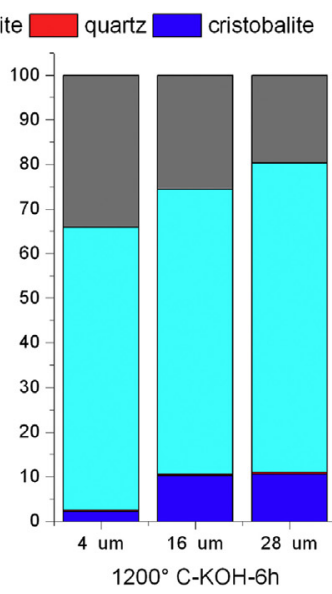

(b) $\mathrm{NaOH}$

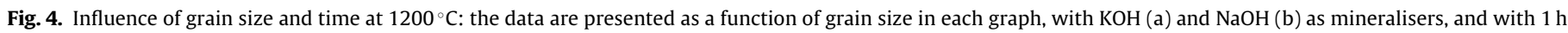
soaking time on the left hand side of each half, $6 \mathrm{~h}$ soaking time on the right.

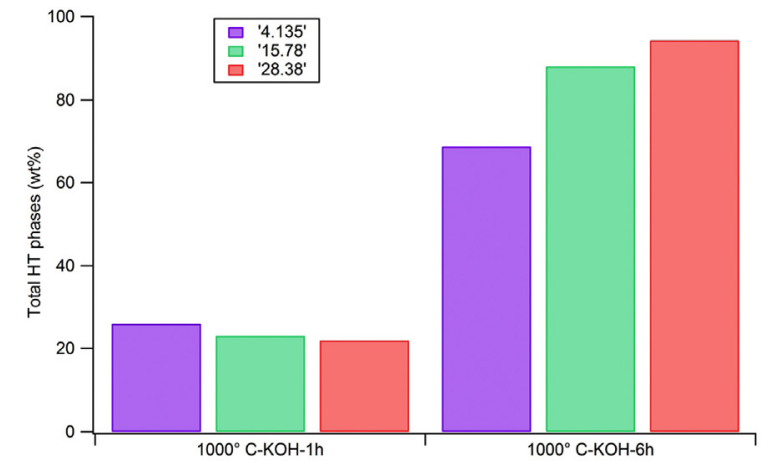

(a) $\mathrm{KOH}$

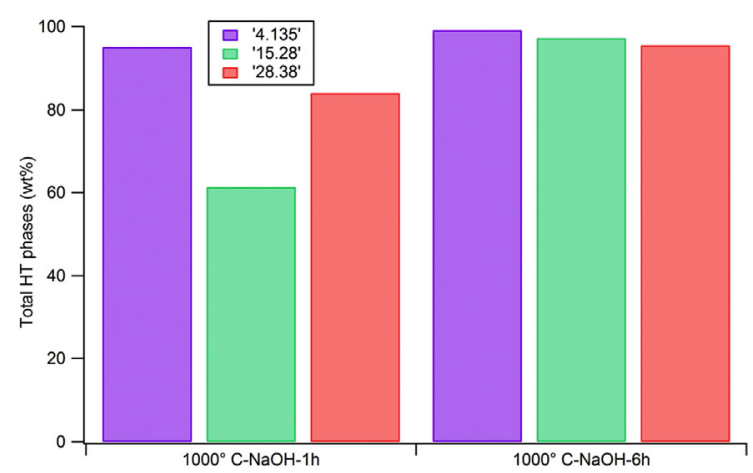

(b) $\mathrm{NaOH}$

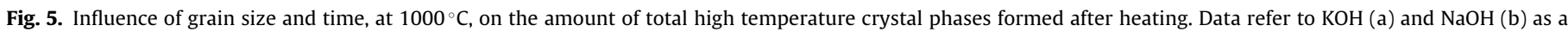
mineraliser. Each left hand side of half figure shows results obtained after $1 \mathrm{~h}$ soaking time; each right hand side is relative to $6 \mathrm{~h}$ soaking time. 


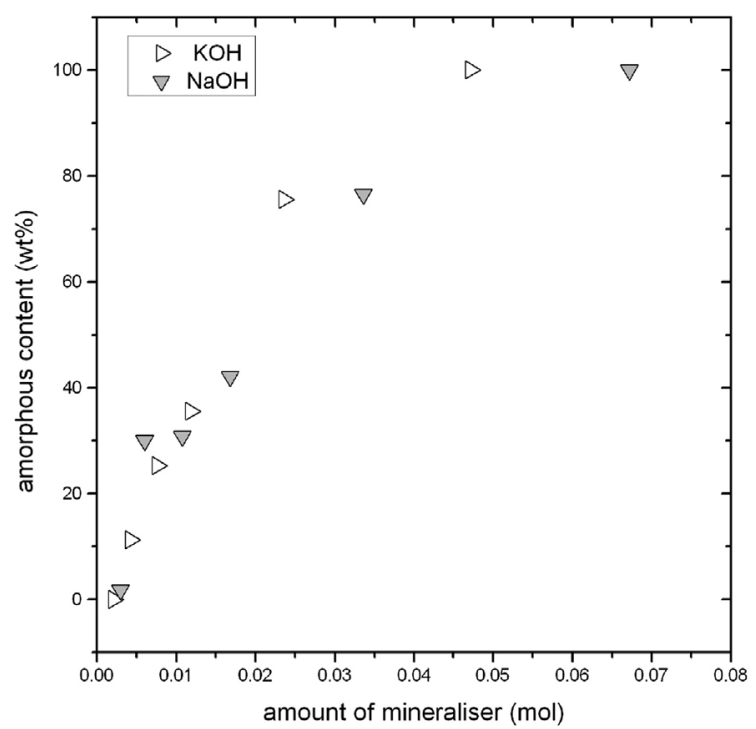

(a) amorphous

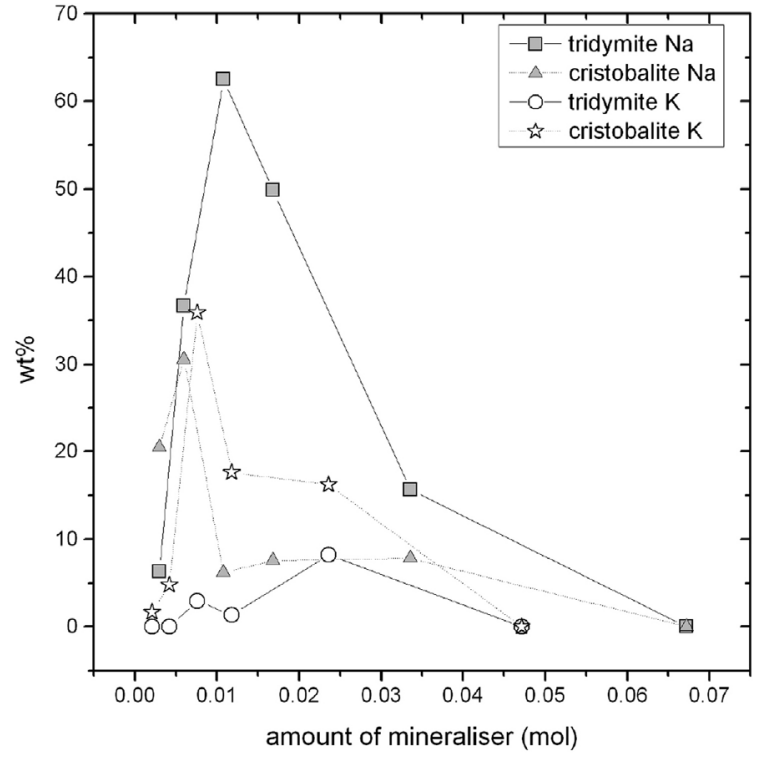

(b) crystalline

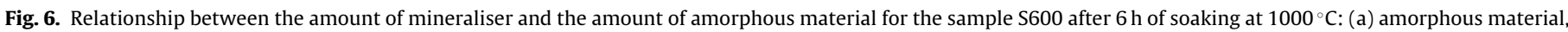
(b) crystalline material.)

experiments, still the mechanism of stabilisation of the high temperature phases by means of the addition of mineraliser was not completely understood, and at the best of the authors knowledge, not present in the current literature. For this reason, an in situ experiment has been performed, with the aim of mimicking the heating ramp to which the quartz sample was subjected to. Details of the experiment can be found in the experimental section. The finest quartz sample (SA600) was chosen for in situ measurements, as it showed the highest reactivity to heating. Fig. 8 reports the diffraction patterns of the finest quartz sample during the heating ramp, for $\mathrm{NaOH}$ and $\mathrm{KOH}$ as mineralisers. For both mineralisers, cristobalite is the first to appear, with tridymite sprouting later in place of the former, which in turn decreases as a function of the tridymite increase. Quartz (cristobalite) starts disappearing (appearing) at a lower temperature in presence of $\mathrm{NaOH}$ than $\mathrm{KOH}$.

The evolution of the phases during in situ high-temperature experiments was determined by following the integrated intensities of chosen diffraction peaks, as "canonical" Rietveld analysis from diffraction pattern would lead to an overestimation of the occurring phases because of the impossibility to introduce an internal standard that accounts for the amorphous contribution to scattering.

Fig. 9 shows the area of the main peaks of quartz, cristobalite, and tridymite with increasing temperature. It definitely confirms that cristobalite is the first phase to form from quartz, and its amount starts decreasing after the appearance of tridymite. Quartz reduces when cristobalite crystallizes, its decrease becomes weaker when tridymite starts to grow and, after the firing process, it is completely replaced by its two high temperature polymorphs, which are present in similar amounts (the room temperature amount of the crystalline phases is represented by the larger symbol at about $1300{ }^{\circ} \mathrm{C}$ in Fig. 9). Tridymite and cristobalite formation is always promoted by $\mathrm{NaOH}$, because reactions are faster (the slopes are much steeper) and take place at lower temperatures. Moreover, the use of any mineralizing agent decreases the crystallisation temperature of cristobalite (of about $300^{\circ} \mathrm{C}$, if compared to the one of pure quartz [7]). The in situ experiments showed that tridymite,

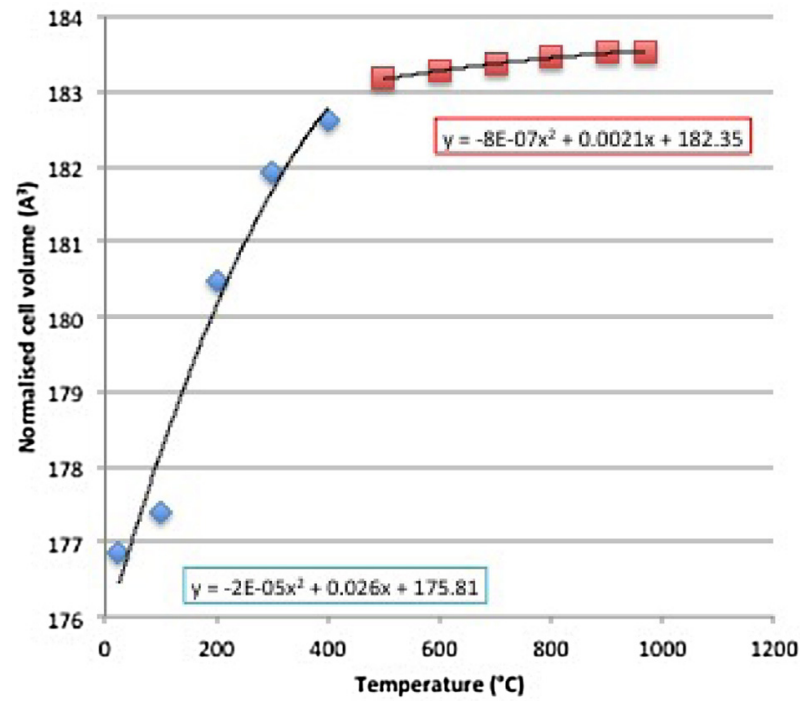

Fig. 7. Cell volume of tridymite, normalised to the number of formula units.

in presence of a mineralising agent, forms from cristobalite, which is the first high temperature phase to appear during heating, even though, according to the silica phase diagram, it should not be stable until about $1450^{\circ} \mathrm{C}$. In the temperature range studied, the thermodynamically stable phase is therefore tridymite. The presence of cristobalite at so "low" a temperature can likely be ascribed to a stabilising effect due to Na and K. As shown in Fig. 1, cristobalite and tridymite bear "cage-like" cavities, which can host alkali-metal ions (see Venezia et al. for example [10]), which yield an increase of the cell volume, that can be related to the total amount of phase formed. This is shown in Fig. 10(b): the cell volume of cristobalite is maximum when cristobalite starts to from (and it is then present in small quantities), and it decreases as the amount of cristobalite increases (i.e. when tridymite starts to form at the expenses of cristobalite). The dashed line represents the cell volume of ideal 


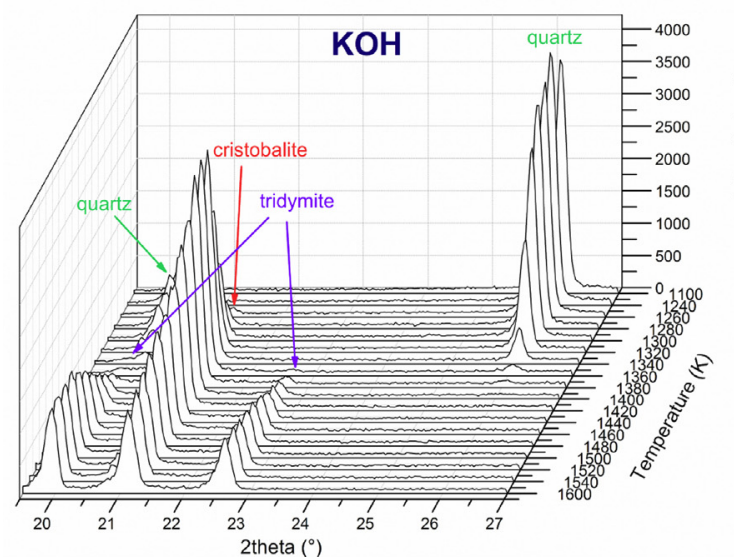

(a) $\mathrm{KOH}$

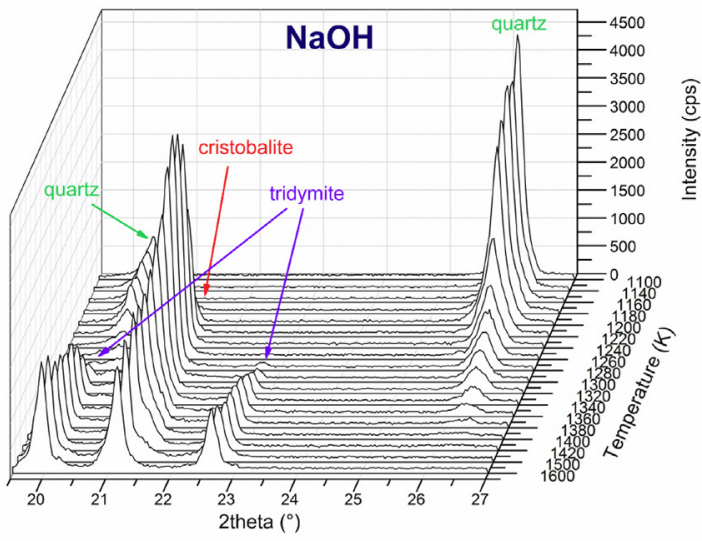

(b) $\mathrm{NaOH}$

Fig. 8. Heating ramps for the finest sample $(4 \mu \mathrm{m})$, with (a) $\mathrm{KOH}$ and (b) $\mathrm{NaOH}$ as the mineraliser.

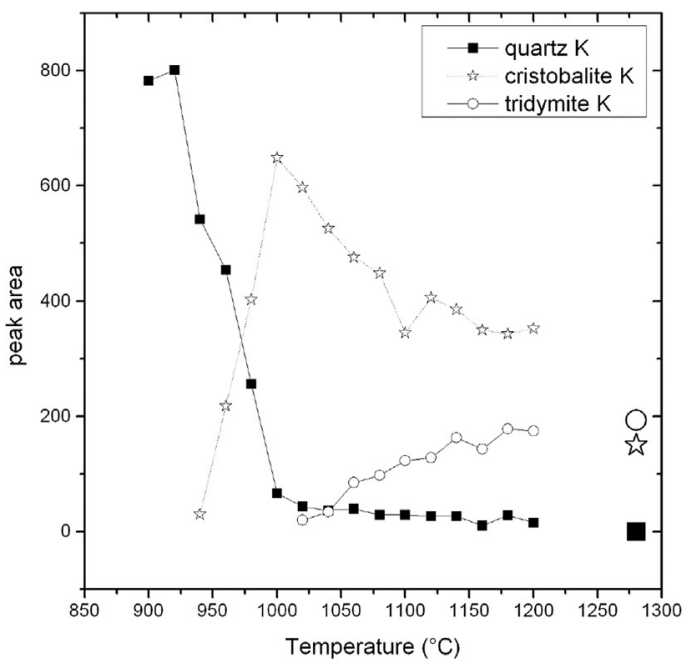

(a) $\mathrm{KOH}$

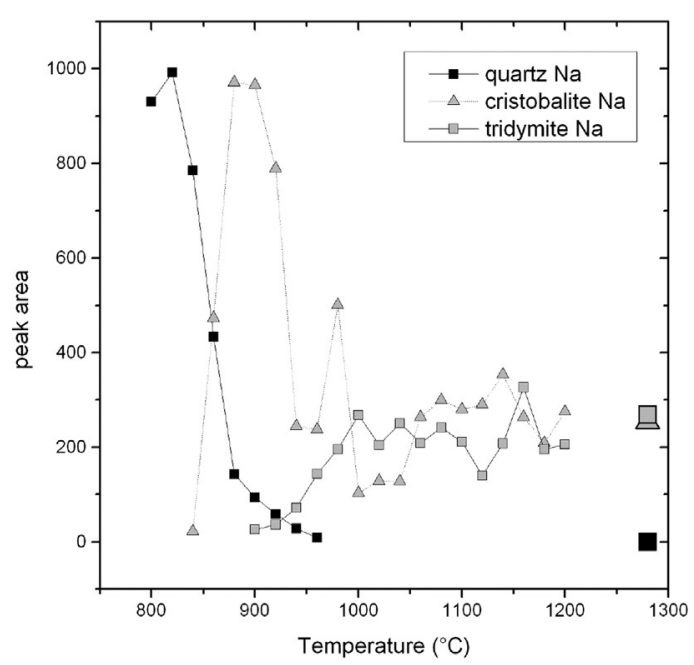

(b) $\mathrm{NaOH}$

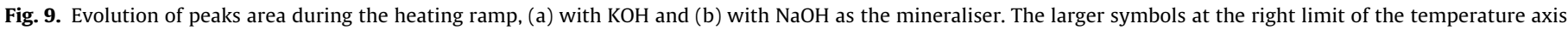
represent the peak areas evaluated at room temperature after the heating ramp.

cristobalite, from ICSD nr. 77452. Fig. 10(a), in turn, shows that the cell volume of tridymite increases along with its amount in the sample; this takes place by depleting cristobalite of alkali-metal ions, which make such phase unstable and lead to a decrease of its content in the mixture.

\subsection{Calculation results}

Calculations were performed using the following defect formation scheme: each alkali-atom included in the calculation corresponds to the removal of a $\frac{1}{4}$ of silicon atom. The energy of formation of the defect is calculated in the following way:

$E_{f}=E_{d}+E_{\mathrm{Si}}-4 \times E_{\mathrm{Na} / \mathrm{K}}-E_{p}$

where $E_{f}$ is the energy of formation of the defect, $E_{d}$ is the energy of the defective system, $E_{p}$ is the energy of the ideal system, $E_{\mathrm{Si}}$ is the energy of the isolated silicon atom, $E_{\mathrm{Na} / \mathrm{K}}$ is the energy of the isolated $\mathrm{Na} / \mathrm{K}$-atom.

The results are shown in Table 2. The structure used is the same used in the Rietveld refinements.
The energy calculations show that:

- Na gives $E_{f} \mathrm{~s}$ smaller than $\mathrm{K}$, and in such a view one roughly expects sodium to be incorporated by the high temperature $\mathrm{SiO}_{2}$ polymorphs more easily than potassium. This aspect might be related to the fact that $\mathrm{Na}$ is more effective than $\mathrm{K}$ to stabilise cristobalite/tridymite even at comparatively "low" temperatures;

- the defect formation energy values suggest that both $\mathrm{Na}$ and $\mathrm{K}$ promote cristobalite, with respect to tridymite. This is consistent with that one observes cristobalite appearing in an interval where tridymite should be the thermodynamically stable phase, i.e. $870-1470{ }^{\circ} \mathrm{C}$. At higher temperatures, when thermal contribution to Gibbs energy is larger than the one of the static component, tridymite occurs;

- the defect formation energies between cristobalite and tridymite differ by about $6 \%$ and $42 \%$, in the case of $\mathrm{Na}$ and $\mathrm{K}$, respectively. Such point suggests that $\mathrm{K}$ discriminates more between cristobalite and tridymite than Na does. Such aspect might be related to the fact that $\mathrm{K}$ provides the largest observed content of cristobalite in the experiments here discussed. 


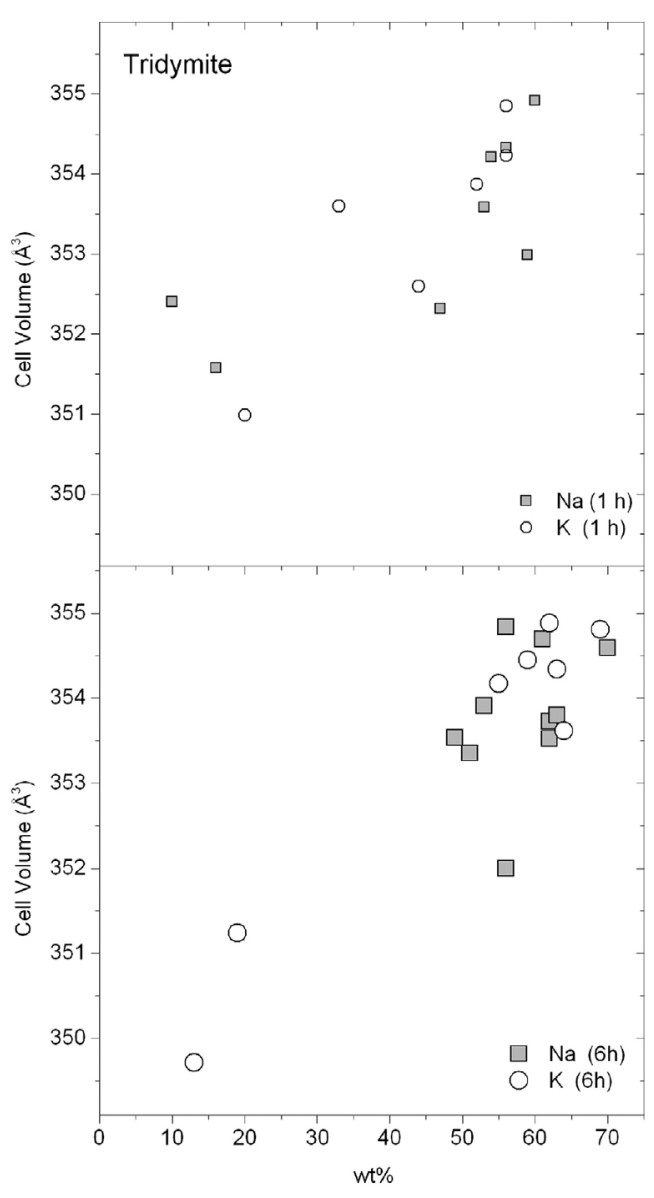

(a) tridymite

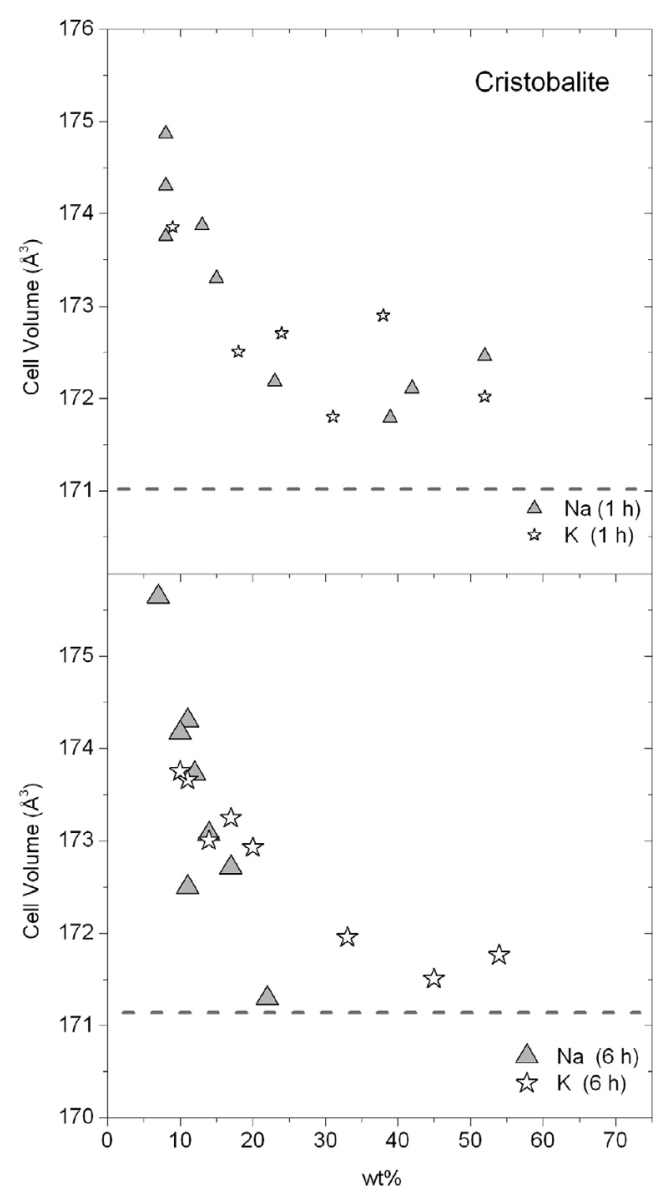

(b) cristobalite

Fig. 10. Relationship between the cell volume of the high temperature polymorphs and their quantity in the samples.

Table 2

Calculation results, in terms of energy of formation (eV per defect) of the defect described in the text.

\begin{tabular}{llc}
\hline Structure & Cation & $E_{f}(\mathrm{eV} / \mathrm{f} . \mathrm{u})$. \\
\hline Cristobalite & $\mathrm{Na}$ & -21.559 \\
Cristobalite & $\mathrm{K}$ & -4.921 \\
Tridymite & $\mathrm{Na}$ & -20.362 \\
Tridymite & $\mathrm{K}$ & -3.221 \\
\hline
\end{tabular}

\section{Conclusions}

This paper shows that the stability of high-temperature silica polymorphs can be influenced by planned amounts of mineralising agents, such as $\mathrm{Na}$ and $\mathrm{K}$. Their presence and quantity in a ceramic body of sanitary-ware affects its thermal expansion behaviour. Starting from industrial-grade quartz, of various grain sizes $(4 \mu \mathrm{m}$, $16 \mu \mathrm{m}$, and $28 \mu \mathrm{m}$ ), exploring two temperatures and soaking times, and adding $\mathrm{NaOH} / \mathrm{KOH}$, we obtain results that can be summarised as:

- the presence of $\mathrm{Na} / \mathrm{K}$ promotes the formation of the hightemperature silica polymorphs at considerably lower temperatures with respect to pure quartz;

- Na starts to form high temperature polymorphs at a lower temperature with respect to $\mathrm{K}$, with quartz disappearing at a very early stage;
- in situ measurements show that cristobalite is always the first phase to form, followed by tridymite that develops at the expenses of the former;

- the amount of amorphous material can be related to the amount of mineraliser $(x)$ added through a quadratic in $x$, for both mineralising agents;

- in view of the points above, the final amount of tridymite, cristobalite and amorphous material can be easily controlled by means of proper time/temperature/mineraliser conditions;

- the volumetric thermal expansion coefficient of tridymite has been measured to be $147 \times 10^{-6}$ until $400^{\circ} \mathrm{C}$, and $11.5 \times 10^{-6}$ beyond $500^{\circ} \mathrm{C}$;

- the defect formation energy (replacement of one Si-atom with four alkali-atoms) suggests that cristobalite is promoted by both $\mathrm{Na}$ and $\mathrm{K}$, in agreement with the fact that cristobalite is always first to form, even in a temperature range where tridymite ought to be stable;

- from the differences between the defect formation energies of both high temperature polymorphs, it can be evinced that K discriminate more between the two structures, with respect to $\mathrm{Na}$, in agreement with the fact that $\mathrm{K}$ forms the largest observed amount of cristobalite.

Bearing in mind that the interaction of $\mathrm{Na}$ and $\mathrm{K}$ with a complete ceramic mixture at high temperature is still largely unknown, this paper demonstrates that the high temperature silica polymorphs formation from quartz is easily controllable by means of the addition of known amount of mineralisers. Even though their effect 
will probably be different in the more complex environment of a real ceramic mixture, this mechanism can be exploited in the production of tridymite and/or cristobalite to be added to the ceramic mixture with the aim of controlling its thermal expansion.

\section{Acknowledgements}

The authors would like to thank Gianluca Maietta for his valuable experimental work in sample preparation, and the ESRF for beam time during experiment MA2315.

\section{References}

[1] A. Nukui, H. Nakazawa, M. Akao, Thermal changes in monoclinic trydimite, Am. Mineral. 63 (1978) 1252-1259.

[2] P.J. Heaney, Structure and chemistry of the low-pressure silica polymorphs, Silica: Phys. Behav. Geochem. Mater. Appl. 29 (1994) 1-40.

[3] M.T. Dove, A.K.A. Pryde, D.A. Keen, Phase transitions in tridymite studied using 'Rigid Unit Mode' theory, Reverse Monte Carlo methods and molecular dynamics simulations, Mineral. Mag. 64 (2) (2000) 267-283.

[4] D.C. Palmer, Stuffed derivatives of the silica polymorphs, in: Silica: Physical Behavior, Geochemistry and Materials Applications; vol. 29 of Reviews in Mineralogy, 1994, pp. 83-122.

[5] A. Putnis, Introduction to Minerals Sciences, Cambridge University Press, 1992.

[6] M. Moseman, K. Pitzer, Thermodynamic properties of the crystalline forms of silica, J. Am. Chem. Soc. 63 (1941) 2348-2356.

[7] L. Pagliari, M. Dapiaggi, A. Pavese, F. Francescon, A kinetic study of the quartzcristobalite phase transition, J. Eur. Ceram. Soc. 33 (2013) 3403-3410.

[8] P. Richet, Y. Bottinga, L. Denielou, J. Petitet, C. Tequi, Thermodynamic properties of quartz, cristobalite and amorphous $\mathrm{SiO}_{2}$ : drop calorimetry measurements between 1000 and $1800 \mathrm{~K}$ and a review from 0 to $2000 \mathrm{~K}$. Geochim. Cosmochim. Acta 46 (1982) 2639-2658.

[9] V. Hill, R. Roy, Silica structure studies vi. on tridymites, Trans. Br. Ceram. Soc. 57 (1958) 496-510

[10] A.M. Venezia, V.L. Parola, A. Longo, A. Martorana, Effect of alkali ions on the amorphous to crystalline phase transition of silica, J. Solid State Chem. 161 (2) (2001) 373-378.

[11] O. Alharbi, D. Zaki, E. Hamzawy, Effect of $\mathrm{TiO}_{2}$, $\mathrm{LiF}$ and $\mathrm{Cr}_{2} \mathrm{O}_{3}$ in the crystallization of cristobalite and tridymite in sintered glass-ceramics, Silicon 4 (2012) 281-287.

[12] Y. Fei, Thermal expansion. In: Mineral Physics and Crystallography: A Handbook of Physical Constants; vol. 2. Ahrens, T. J., AGU Reference Shelf, 1995, pp. 29-44.

[13] J.F. Shackelford, R.H. Doremus, Ceramic and Glass Materials, Springer, 2008.

[14] R. Dovesi, V. Saunders, C. Roetti, R. Orlando, C.M. Zicovich-Wilson, F. Pascale, et al., CRYSTAL09 User's Manual, University of Torino, Italy, 2009,

[15] M. Ferrari, L. Lutterotti, Method for the simultaneous determination of anisotropic residual stresses and texture by X-ray diffraction, J. Appl. Phys. 76 (11) (1994) 7246-7255.

[16] A.F. Gualtieri, Accuracy of XRPD-QPA using the combined Rietveld-RIR method, J. Appl. Crystallogra. 33 (2000) 267-278.

[17] A. Bernasconi, M. Dapiaggi, A.F. Gualtieri, Accuracy in quantitative phase analysis of mixtures with large amorphous contents. the case of zircon-rich sanitary-ware glazes, J. Appl. Crystallogr. 47 (2014) 136-145.

[18] A.N. Fitch, The high resolution powder diffraction beam line at ESRF, J. Res. Natl Inst. Stand. Technol. 109 (2004) 133-142.

[19] I. Scanavino, M. Prencipe, Ab-initio determination of high-pressure and high-temperature thermoelastic and thermodynamic properties of low-spin $\left(\mathrm{Mg}_{1-x} \mathrm{Fe}_{x}\right) \mathrm{O}$ ferropericlase with $x$ in the range 0.06, 0.59., Am. Mineral. 98 (2013) 1270-1278

[20] Z. Wu, R. Cohen, More accurate generalized gradient approximation for solids, Phys. Rev. B B73 (2006) 235116.

[21] C. Lee, W. Yang, R. Parr, Development of the Colle-Salvetti correlation-energy formula into a functional of the electron density, Phys. Rev. B B37 (1988) 785-789. 